\title{
Um mercenário alemão devora o Brasil, e nos conta
}

\author{
Tales Ab'Sáber
}

RESUMO: C. Schlichthorst, um dos viajantes europeus que nomearam o Brasil dos primeiros tempos em suas memórias de viagem ao país, entre 1824 e 1826, reconheceu elementos sociais importantes da formação escravocrata brasileira e deu formulação direta, reflexiva e quase realista para a experiência do Brasil, de um modo que os próprios brasileiros levariam mais de meio século para se aproximar daquela natureza de forma literária e sua produção de sujeito e vida social. Sua escritura moderna informa o que o país sempre quis esconder e revela que o atraso e a diferença econômica da nação pós-colonial eram também um cuidadoso e cultivado "atraso simbólico" sobre a experiência da sua própria vida.

PALAVRAS-CHAVE: Memórias de viagem; Brasil Império; representação da escravidão; forma literária; literatura brasileira.

\begin{abstract}
C. Schlichthorst, one of the European travelers who named Brazil from the early days in their memories of traveling to the country, between 1824 and 1826, recognized important social elements of the Brazilian slave formation and gave direct, reflective and almost realistic expression to the experience of Brazil, in a way that the Brazilians themselves would take more than half a century to get closer to that nature in literary form and their production. His modern scripture informs what the country has always wanted to hide and reveals that the delay and economic difference of the colonial nation was also a careful and cultivated "symbolic delay" on the experience of his own life.
\end{abstract}

KEYWORDS: Memories of Travel; Brazil Empire; representation of slavery; literary form; Brazilian literature. 
O Rio de Janeiro como é foi escrito por um militar alemão popular cheio de espírito, mesmo que de superfície, e pleno de curiosidade, ainda que determinada pelo interesse próprio, para dar notícia ampla de sua experiência, entre 1824 e 1826, no Brasil, novíssimo país americano que despontava então no horizonte das nações modernas. ${ }^{1}$ Schlichthorst foi um dos mercenários, soldados treinados que restaram sem trabalho após o fim das guerras napoleônicas, seduzidos e embarcados rumo ao país americano pelo duvidoso agente imperial von Schaffer - amigo íntimo de nossa imperatriz austríaca - cujas mentiras visando a atrair a escória alemã para formar as tropas estrangeiras do novo Império lhe valeram a alcunha de carniceiro de gente.

E, de fato, numa das muitas surpresas do relato do viajante sobre a sua experiência com o novo país - publicado em 1829 em Hannover através da subscrição de amigos -, ele nos conta a história de como o navio que o trouxera, bem como a outros futuros militares do Império tropical recém-fundado, se aproximava constantemente, por vezes, de se converter em uma espécie de navio de escravos - uma fantasmagoria dos mares mundiais que moveu toda a expansão do capitalismo mercantil desde o século XVI até o final do XIX - pelos modos totalitários dos contratantes e para a revolta de muitos dos contratados para a desconhecida vida nova no Brasil... Mary Karasch lembra, exatamente, que a experiência da importação de homens livres da época, mercenários, foi encerrada com importantes sublevações das tropas estrangeiras, que se sentiam ao final da história, no fim daqueles mesmos anos de 1820 , exatamente tratadas como escravos pelo oficialato do Império do Brasil...2

Schlichthorst também foi aquele interessante escritor que, conhecendo o país desde as ruas de sua Corte nos seus primórdios, comentou as primeiras impressões e hipóteses sobre a natureza e o futuro da literatura brasileira que, ao seu tempo, estava toda por ser inventada. Seu pequeno tratado de teoria literária do Brasil era um trabalho retrospectivo de história da literatura colonial local, uma parte das suas memórias cariocas, um estudo especulativo sobre a ordem simbólica possível do novo país, também, em parte, por ser inventado, a respeito do qual Antonio Candido escreveu, com um mínimo grão de admiração e um tanto de respeito:

1. SChlichthorst, C. O Rio de Janeiro como é, 1824-1826: uma vez e nunca mais. Tradução de Emmy Dodt e Gustavo Barroso. Rio de Janeiro: Editora Getulio Costa, s.d. [1943]; [Rio de Janeiro: Senado Federal, 2010].

2. Karasch, Mary C. A vida dos escravos no Rio de Janeiro. São Paulo: Companhia das Letras, 200o, p. 126. 


\begin{abstract}
Alguns viajantes estrangeiros se referem ao passado literário do Brasil ou auguram o desenvolvimento de uma literatura original, quando não fazem as duas coisas ao mesmo tempo.// Ninguém no primeiro sentido foi mais minucioso, interessado e simpático do que o alemão Schlichthorst, oficial nos corpos estrangeiros no Exército Imperial de 1824 a 1826, que publicou em 1829 um dos livros mais interessantes sobre o país [...].// Mesmo que os brasileiros não tenham tomado conhecimento da sua obra, escrita em alemão e a que não há referências no tempo, ela representa bem claramente o que nos interessa verificar: a noção da existência de uma continuidade literária e a formulação de princípios que deveriam caracterizar as novas tentativas literárias. ${ }^{3}$
\end{abstract}

Diferentemente das hipóteses ideológicas abstratas então em voga, não por acaso, sobre como narrar e inventar o Brasil e seu mundo, havia por parte do viajante e soldado alemão um interesse sobre as origens e o destino da literatura possível no novo país americano, uma real intuição de um movimento histórico próprio, de um escritor que se dedicou a escrever o Brasil ao seu próprio modo.

E, de fato, nas interessantíssimas memórias brasileiras de Schlichthorst lemos e ficamos sabendo, em um traço límpido e preciso, que, para a honra do novo país, na sua grande Corte, a cidade do Rio de Janeiro:

Os traficantes de escravos são considerados os negociantes mais ricos da cidade. Habitam quase exclusivamente as ruas do Valongo, do Aljube e algumas outras nas proximidades do porto. Muitas de suas casas, que podem ser considerados verdadeiros palácios, têm a mesma disposição no andar térreo: largo vestíbulo dando para pequenos pátios, onde nada mais se vê além de bancos baixinhos. São o chamado armazém de depósitos de escravos, geralmente muito limpo, de chão lavado e varrido várias vezes por dia. A fresca brisa do mar sopra por toda parte, de maneira que, mesmo quando cheio de negros, pouco se sente o mau cheiro que caracteriza as cadeias e casas de detenção da Europa. ${ }^{4}$

É significativo o movimento de tolerância e entendimento que move o mercenário prussiano, que parecia, com grande ambivalência, buscar se abrasileirar na medida do que

3. CANDido, A. Formação da literatura brasileira. São Paulo: Martins Fontes, 1959, vol. 1, p. 302.

4. SCHLichthorst, C. Op. cit., p. 129. 
lhe era possível, quando ele descreve o catálogo da vida civil sob o regime da escravidão brasileira dos anos 20 do século XIX - de fato o momento literário mais próximo da real civilização portuguesa tropical já instalada por aqui, herdada como mentalidade original, modo de ver e de agir que - na radical, inventiva e psicanalítica hipótese glauberiana de Terra em transe - tem longa duração e costuma retornar, particularmente em tempos de crise e de ruptura, como forma específica de resistência nacional.

O texto do alemão une, de modo bastante original, o armazém de escravos, a casa senhoril ampla, luxuosa e asseada ao modo tropical e a brisa fresca da grande cidade portuária, que beija e balança uma vida que quase chegamos a sentir, uma vida que deseja ser estável e digna, de modo contínuo e contíguo à sua própria ignomínia. Barbárie e civilização tropical, violência consentida generalizada e privilégios fantásticos dos senhores, luxo e escravidão, já andavam bem unidos, e o estilo límpido e realista do estrangeiro acentua a integridade, já quase estética, de tal mundo fortemente duplicado, mas de fato uno. Um mundo violento ao extremo frente à sua mão de obra produtiva, mas civilizado.

Curiosamente já parece haver alguma bossa brasileira nesta literatura de nossos primeiríssimos tempos, e o esforço em civilizar a vida escravocrata brasileira, e ser civilizado por ela, faz balanço, leve, rápido, mas preciso, como o vento, com a crítica atualizada aos momentos bárbaros de uma Europa que, surpreendentemente, do ponto de vista do projeto ideológico periférico, e de seu imigrante pobre, já não se apresentava exatamente como modelo. $\mathrm{O}$ escritor não se aterroriza diante da escravidão brasileira, e não a descreve em registro de inominável e irrepresentável barbárie. As cadeias da Europa - exatamente as mesmas estudadas por Foucault com enormes consequências para o entendimento do desenvolvimento do poder na modernidade - cheiravam pior do que os nossos armazéns de escravos, dizia um pobre-diabo em trânsito global, que provavelmente as conheceu. Será de fato em geral leve, quase descomprometida, a visão de Schlichthorst da cultura brasileira dos primeiros tempos, para ele um mundo especialmente gracioso e erótico de modo particular, vital e jovem, desde que se aceite como parte de tal encantamento, como vemos na passagem do sobrado armazém dos comerciantes cariocas, a naturalidade da escravidão onipresente. Ela fala de um mundo, e de um modo, que lembra muito bem os mexericos e a excitação superficial das jovens personagens de José de Alencar, de trinta ou quarenta anos depois, em seus romances urbanos ou até mesmo naqueles passados em venerandas fazendas imperiais, onde, de fato, diferentemente do alemão, apenas os escravos que se aproximavam da cozinha existiam, um pouco, para aquela escritura. 
Assim, Schlichthorst pode ainda ir mais longe, e ensinar que o Brasil com sua ordem escravista era um caso concreto e objetivo de civilização que, se parecia desvio e discutível, e efetivamente o era, tinha dimensão positiva e prática própria:

Entre os muitos milhares de escravas jovens que perambulam pelas ruas do Rio de Janeiro vendendo flores e frutas, talvez não se encontre uma só que recuse um convite para isso [relações sexuais]. Muitos europeus sentem aversão natural pelas raparigas pretas, mas, desde que a vençam, passam a gostar delas. Demais, há umas de feições tão lindas, de estrutura de membros tão esplêndida e de tanta frescura que se torna difícil resistir à tentação de possuir todos estes encantos por alguns vinténs. ${ }^{5}$

Para dar ao bondoso leitor uma ideia aproximada da confortável vida meridional, tentarei fazer o resumo de um dia como, sem grandes despesas, os estrangeiros desocupados podem usufruir no Rio de Janeiro. Muitos acharão esta vida fastidiosa, mas são os que nunca experimentaram a deliciosa plenitude do dolce far-niente. Os raios do sol nascente entram no quarto pelos batentes abertos do balcão. Eu, como verdadeiro filho do Norte, que nunca fui amigo de acordar cedo, viro-me mais de uma vez na cama. Mas a fantasia pinta à minha inata preguiça os encantos de uma bela manhã, com as mais sedutoras cores, o bom senso a auxilia com algumas razões higiênicas e, assim, ela é vencida mais depressa e mais facilmente do que supunha. ${ }^{6}$

De modo significativo, os traços brascubianos deste discurso original sobre o Brasil já são acentuados - e aqui, como também ocorre no jovem José Alencar de Ao correr da pena, de 1854, o volúvel personagem Brás Cubas de Machado de Assis é o próprio sujeito da enunciação que, além de narrador, responde ao que fala como um eu, instâncias que gozam o direito contraventor real de nada fazer, da preguiça senhoril, ao mesmo tempo que de algum modo a notam como desvio moderno local, próprio de uma economia na qual quem trabalha são os escravos reais - e cada vez mais podemos compreender o quanto Machado de Assis apreendeu em profundidade histórica, em conjunto com a poderosa e extensa novidade da sua linguagem, o espírito e a formação de nossa ambígua elite imperial, e da nação. De fato, todos que se aproximavam do Império politicamente insólito, mas socialmente radical, do Brasil do século XIX, e que tenta-

5. SCHLichthorst, C. Op. cit., p. 135.

6. Idem, p. 83 . 
vam enunciá-lo com correção realista, se aproximavam espontaneamente do vértice da volubilidade, social, política e simbólica brasileira, em um fenômeno de força de imposição de uma realidade histórica sobre seus sujeitos e enunciadores muito notável.

Muito rapidamente, Schlichthorst aprende que a vida da elite nacional é a sustentação ideológica, graciosa ou cínica, tanto faz, de um estado de coisas em que os benefícios e privilégios são expressivos e singulares, incluindo aí vantagens e práticas simplesmente vedadas ao processo civilizatório do século do Capital e do mercado europeu, liberal, puritano já há séculos, e, gradualmente, burguês, vitoriano e, por fim, de mercado de massas. E também de luta de classes. Baseado na escravaria, e esquecendo o seu destino real - que, segundo o próprio Schlichthorst, morria então, na cidade, por volta dos trinta e cinco anos... - um homem livre, senhor brasileiro urbano, podia dedicar-se tranquilamente à preguiça, à vida levada na flauta, como passeio, ao uso erótico do corpo da escrava, se acaso o desejasse, e à graça distraída de uma civilização irresponsável, mas feliz. À deliciosa plenitude de nada fazer, em pleno século XIx. De fato, tudo indica, o Brasil já constituía fortemente então um estatuto singular de biopolítica, único no processo da modernidade ocidental: eram os corpos, os tempos e os usos da vida, tanto de senhores quanto de escravos, que se contrapunham e que se constituíam, como prática, em tal processo histórico que acumulava, de modo não íntegro, mas plenamente realizado como civilização, a sua alegria com o seu próprio terror.

Por outro lado, o imigrante soldado autor afirma também, de modo aberto e claro único no século xix brasileiro, a presença de vida sexual negociada e amplamente disponível entre os homens livres e as escravas de ganho que circulavam com certa liberdade pelas ruas do Rio de Janeiro. Segundo ele, possivelmente não havia uma mulher negra escrava de ganho que, vendendo frutas ou flores, doces ou água, recusasse trocar alguns vinténs por algum sexo. Assim, a cultura popular da rua do Rio de Janeiro seria também uma imensa negociação sexual, certamente de pouco ganho e movimento social para as mulheres negras envolvidas. Schlichthorst, que aparentemente não tinha os impedimentos católicos em nomear coisas sexuais com o próprio nome, retomava uma questão real que a lírica seiscentista de Gregório de Matos, de seu ponto de vista concreto interessado na vida mundana e citadina na Bahia, já havia assinalado, duzentos anos antes, a respeito da escravidão urbana da então colônia e sua vida, em um discurso isolado em relação à máquina ideológica colonial hegemônica - católica e burocrática -:

Mulatinhas da Bahia

que toda a noite em bolandas 


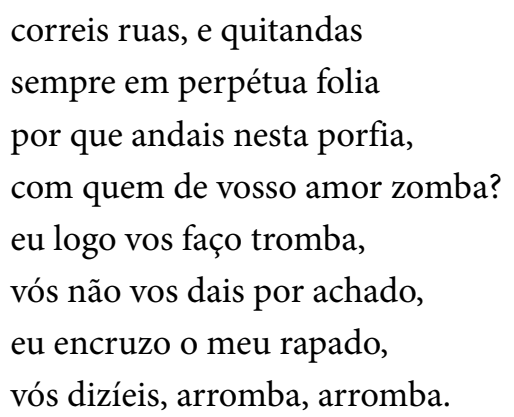

Luiz Felipe de Alencastro, comentando esses versos, relembra que no Brasil ocorreu um fenômeno de formação de vida social, definido pelo sistema de interesses dos senhores e pela opressão do sistema do escravismo colonial, que transformou a miscigenação típica das violências coloniais em mestiçagem, configurando um processo histórico particular, complexo, que daria origem à nossa sociedade multirracial. E conclui com o que importa a este respeito: "o fato de este processo ter se estratificado e, eventualmente, ter sido ideologizado, e até sensualizado, não se resolve na ocultação de sua violência intrínseca, parte consubstancial da sociedade brasileira".

\section{II}

Para completar o quadro com bastante precisão frente às mazelas de longuíssima duração de nossa vida civil incivil, Schlichthorst, o soldado alemão agregado às tropas brasileiras, um possível protobrasileiro que fazia cálculos com juros para saber quanto enriqueceria em vinte anos se investisse em escravos no Brasil, concluindo ser um negócio bastante razoável, tem também o seu verdadeiro vislumbre do paraíso, de uma ordem muito especial e profunda de violências que começava então a ser festejada.

Por mais dura que seja a um ouvido europeu a palavra escravidão, esse estado é, na América do Sul, em geral suportável. O português e o espanhol tratam bem seus escravos, sem dúvida melhor do que o plantador das Índias Ocidentais, seja inglês, holandês ou francês. Na cidade, o escravo é senhor de seu nariz e cuida de sua vida sem sujeição de qualquer violência. Não são grandes suas necessidades, e seus gozos nada lhes custam.

7. Alencastro, Luiz Felipe de. O trato dos viventes. São Paulo: Companhia das Letras, 200o, p. 353. 
Qualquer terreno baldio vale por uma sala de baile, qualquer rapariga torna-se a dama do seu coração e, se de quando em vez necessita dum incitamento à alegria, encontra em todas as vendas, como bebida predileta e baratíssima, a cachaça. ${ }^{8}$

A longa duração desta noção, tão ideológica quanto concreta, a respeito do que viria a ser o povo brasileiro, impressiona. Segundo o relato, o escravo urbano brasileiro, já na sua origem, era uma espécie de meio sujeito, de uma vida meio cativa, produzindo experiências urbanas de um certo erotismo, singular e concreto. Sua vida também era marcada por próprias vantagens, produto de uma civilização ocidental particular, não constituída de forma excessivamente rígida. Desse modo, um terreno baldio é uma sala de baile, realizando uma imagem erótica e onírica pré-moderna brasileira, uma imagem dialética forte de nossa civilização da precariedade que vai atravessar grande parte de nossas ilusões e pesquisas estéticas e civilizatórias posteriores, já de cunho modernista.

É do espaço indeterminado de uma civilização incivil nos termos dos direitos universais, mas também incorrespondente às específicas violências superestruturadas modernas europeias, que surge a utopia de nossa expressão erótica concreta, junto à natureza e ao próprio gesto e corpo, como civilização. E o negro escravo, semiautônomo da cidade, mas escravo na apropriação absoluta do valor de seu trabalho, é o corpo social que expressa essa civilidade erótica moderna, utópica de um modo próprio, e radical.

Um terreno baldio, uma rapariga e um pouco de cachaça, na insolidez geral do país, produzem a vida do espírito nova de um povo cujo real estatuto jurídico é o de escravo, o que, segundo o soldado alemão, não deveria soar muito duro aos ouvidos europeizados, parciais. Neste mundo, para este povo, realiza-se uma modalidade precoce de onirismo moderno, baseado nas chibatas reais, em que um terreno baldio é um salão de baile. $\mathrm{Ou}$, de outra perspectiva, tratava-se de uma cultura lúdica, compensatória do terror, que operava com as mesmas potências criativas na ilusão - que não equivale à mentira, lembra-nos Donald Winnicott. E o que mais este tipo original de deslocamento simbólico era capaz de produzir?

Esta concepção das coisas do Brasil, da cultura espontânea popular e erótica, estará presente, por exemplo, desde o samba urbano e seu carnaval até a poesia pau-brasil e o Macunaíma, dos nossos grandes modernistas, dos bólides e dos parangolés de Hélio Oiticica - uma palavra o artista recolheu junto a um mendigo, um negro velho... e

8. SChlichthorst, C. Op. cit., p. 132. 
uma obra-corpo que fazia exatamente com que qualquer terreno baldio fosse um salão de baile... Todas estas são obras e mundos avançados que pesquisaram e se constituíram diante e na civilização da precariedade brasileira, uma experiência popular original que se tornou pedra de toque da vanguarda futura possível.

E, enfim, no estudo social incorporado de Schlichthorst, surge a fala original da cultura brasileira, o primeiro resultado daquela mesma África que um dia civilizaria o Brasil, segundo o político conservador imperial, escravista, Bernardo Pereira de Vasconcelos:

O canto, a dança e os folguedos enchem as horas de folga dos escravos. Quando se quer ver gente alegre, basta procurá-los. De natureza é o brasileiro melancólico, muito sensual, cerimonioso, e desconfiado, qualidades essas que não produzem a verdadeira alegria. A inconsciência do negro deixa-lhe gozar do que o momento lhe propicia, sem cuidados sobre o futuro. Sua dança predileta chamava-se fado, e consiste num movimento trêmulo do corpo que, suavemente embalado, exprime os sentimentos mais sensuais de um modo tão natural como indecente. São tão encantadoras as posições desta dança que muitas vezes os dançarinos europeus as imitam no Teatro de S. Pedro de Alcântara, recebendo aplausos entusiásticos.// Encontram-se, entre os negros, excelentes improvisadores. Todos os seus trabalhos, folguedos e danças são acompanhados de cantigas. Todas as impressões que recebem tomam uma forma poética. O pensamento gera a rima, e a rima gera outro pensamento. Estão sempre cantando suas felicidades e suas dores em estâncias mais curtas ou mais longas. ${ }^{9}$

O escritor estrangeiro nota a diferença cultural entre o espírito e os corpos dos senhores e o de seus escravos e observa que, embora desprovidos de direitos civis e de acesso ao espaço público da política e da economia que os implicava, eram os escravos que, com sua dança e sua música, já percebidas como ricas, ocupavam o espaço do mundo da vida e da rua, com elementos simbólicos fortes e novos. Eram eles que produziam o afeto da alegria, que seria ideologicamente tão característico do novo espaço social e nacional. E, com coerência e inteligência quase conceitual, Schlichthorst também concebe uma verossímil teoria materialista para o importante problema da felicidade dos pobres no Brasil, entendida como a inconsciência, ligada a uma hipersensibilidade para o presente, advinda

9. Idem, p. 142 . 
de uma plena consciência sobre não ter futuro. Assim nos oferece uma primeira imagem das práticas de vida criativa, da música misteriosa e mágica, mesmo que feitas à luz do dia e em plena rua, na capital do Brasil, dos reais antepassados dos que um dia seriam os nossos Cartolas, Caymmis e Manos Browns, dando-nos intuição para uma tradição profunda, de longa duração, de uma experiência popular brasileira que explica muita coisa.

O caráter repressivo de uma sociedade racista e religiosamente moral não podia se expressar integralmente então, na totalidade do mundo da vida e da cidade, como ação prática e política, policial, contra a vida cultural de maior erotismo dos pobres, escravos, negros, isto porque, muito provavelmente, em um país que ainda precisava importar até mesmo seu próprio exército por ausência demográfica significativa de um povo livre local, não havia força institucional, burocrática, nem riqueza disponível para a repressão geral de uma ampla expressão popular que se generalizava. Os corpos eram controlados, mas sua expressão não. Além disso, os escravos e escravas eram mandados à viração todos os dias e sua renda possível dependia de algo de seu próprio movimento livre, como se pode observar também no trabalho de Jean-Baptiste Debret no mesmo período. Nessa dimensão da vida, eles eram, por um segundo, quase donos dos seus narizes, nas palavras do soldado alemão. E ainda, sobre a "alegria" dos escravos, segundo o próprio Debret, desde os navios negreiros até os grandes armazéns de negócios do Valongo, o antídoto para a depressão e a desmobilização dos escravos era fazê-los dançar e festejar, em um paradoxo de inversão do sentido das coisas humanas verdadeiramente notável, real brasileiro, biopolítica perversa nacional, jogo entre poder e afeto que deu origem à famosa cena patética limite que Heine figurou em seu poema sobre o navio negreiro internacional: do traficante que obrigava os africanos a festejarem, no mesmo movimento que os escraviza, no navio e no mar que os desterritorializa de tudo, menos disso... ${ }^{10}$

Segundo o soldado alemão brasileiro, toda a experiência da vida negra era figurada, simbolizada, na forma poético musical, de qualidade e inteligência formal. Aquele registro estético-poético, lúdico-erótico, era o modo de uma experiência radical de violência em plena modernidade dizer de si própria, o vértice simbólico, como dizia Bion, que falava a história, o nome e a vida, simultaneamente, daqueles que não conheciam nenhum acesso à cultura letrada, própria do poder que os submetia, ocidental, colonial.

10. Debret, Jean-Baptiste. Org. straumann, Patrick. Rio de Janeiro, cidade mestiça: nascimento da imagem de uma nação. Tradução de Rosa Freire d’Aguiar. São Paulo: Companhia das Letras, 2001, p. 19. 
No Brasil o pensamento popular, e negro e sua metafísica, ontologia e filosofia, sempre foi musical, e também sempre dançou, como um dionisíaco europeu moderno, no limite das contradições de seu próprio espaço histórico, desejou mesmo que Deus o fizesse.

\section{III}

O congelamento do espírito crítico e imaginativo, que correspondia ao congelamento da vida social movida por escravos, que não podia ser pensada, fez com que na primeira metade do século XIX nenhum brasileiro pudesse produzir algum discurso verdadeiramente moderno sobre o assunto, a escravidão, central à vida do país.

Não há registro na época de ninguém que tenha escrito com a liberdade de investigação e inteligência, de modo espontâneo, com traços baudelairianos avant la lettre, algo como o seguinte poema em prosa sobre a experiência de nossa escravidão:

À frente da igreja, um telheiro sustentado por quatro colunas cobre bancos de pedra, que permitem contemplar comodamente a vasta superfície do Atlântico. Em face, boiam no espelho azul do mar ilhas emplumadas de palmeiras e vestidas de vegetação tropical sob o céu límpido e arqueado até o horizonte. Estirado num daqueles bancos, ouvindo o marulhar das ondas, sonhei que estava novamente a bordo e naveguei, com a velocidade do pensamento, de volta à minha terra distante. Então, ouvi pertinho de mim um som de marimba tocada por uma negrinha mimosa, que se aproximara e me oferecera doces. Tinha uma companheira, deitada perto, à sombra da igrejinha, naquela cômoda atitude que caracteriza os africanos. Para não desapontar a menina, comprei um pedaço de marmelada, bebi da sua bilha e pedi-lhe que dançasse. Não se fez de rogada muito tempo, chamou a outra, entregou-lhe a marimba e, à sua música, começou o fado, dança que na Europa seria julgada indecente e que aqui é inteiramente popular entre velhos e moços, brancos e pretos.

Imagine-se uma mocinha na flor da idade, com um corpo soberbamente formado, negra como a noite, o leve vestido de musselina branca caindo negligentemente de um ombro, a carapinha oculta num turbante vermelho, olhos brilhantes como estrelas, a boca fresca como um botão de rosa desabrochando e dentes que ultrapassam as pérolas em brilho e alvura; imagine-se esta mocinha em movimento suavemente embalante, mãos e pés batendo o compasso da dança maravilhosa, ao lado de uma mulher bem nutrida, verdadeira beldade africana, assentada no chão e tocando a marimba com os 
dedos carnudos; ouçam-se os sons do instrumento e o canto que o acompanha; depois olhe-se para mim, comodamente deitado no banco, com o desenfado de um fazendeiro das Índias Ocidentais, tragando e exalando o fumo aromático de um charuto, e se terá visto a cena que pretendo descrever.

A canção que a bela filha da África cantou, enquanto dançava, deveria ser mais ou menos esta:

Na terra não existe céu,

Mas se nas areias piso,

Desta praia carioca,

Penso estar no paraíso!

Na terra não existe céu,

Mas se numa loja piso,

E compro metros de fita,

Penso estar no paraíso! ${ }^{\text {11 }}$

Algumas das dimensões mais profundas da civilização da escravidão dos primeiros tempos do Brasil cabem nestas palavras. E elas nos surpreendem fortemente, por exemplo, ao indicar o amor da jovem escrava, realista, sem recusa da dureza do mundo, pelo espaço erótico e ideológico do novo país, que já a formara e formava. E o ainda mais surpreendente amor pela muito incipiente civilização da mercadoria local, que já parecia então, no início de tudo, convencer muito a moça. A mercadoria, a fita, a vaidade da beleza, o corpo erótico que dança e a sedução vital da garota se comunicam, nesta imagem que condensa muitos mundos, de alguém que recém pisava numa praia que era bem essa.

As quadrinhas populares cantadas pela linda garota escrava, recolhidas pelo escritor/narrador dono de inteligência moderna, têm correspondência social e de algum modo se aproximam em complexidade do poema fundador da sensibilidade romântica, melancólico, do ponto de vista da elite, que foi a famosa pequena obra-prima "Canção do exílio", de Gonçalves Dias. Aquela primeira obra significativa do campo simbólico e imaginário romântico brasileiro, da elite que buscava saber de si e pensar, e que gradualmente se

11. Idem, p. $177,178$. 
aproximava da terra, tem profunda trama dialética interna com aquela pequena visão luminosa da utopia brasileira possível à vida popular da garota escrava. De fato, em ambas as poesias se sonha com uma terra maravilhosa, que tem algum vínculo com o paraíso, e que é bem esta. A moça inteligente que precisa ganhar a vida, e celebra seu poder de sedução encantado com arte, que lhe permite ganhar a vida, canta mesmo um primeiro país tropical, abençoado por Deus, paraíso no qual ela já pisa as areias, mas que, com inteligente ironia, ela sabe bem que não é o céu. Do mesmo modo que a tristeza profunda, embutida no poema emblema do pai de nosso romantismo reflexivo, também o sabe bem, embora o negue relativamente a favor do momento nacionalista que enfeixa a composição. Porém, o desterro da moça é, surpreendentemente, afirmativo, pragmático e positivo, ele está no fundo de um princípio de luta necessária pela vida, que erotiza com clareza o mundo ao redor, a praia, a loja e a fita, em conjunto com o próprio corpo da garota que performa a sua dança... Enquanto a tonalidade elegíaca do exílio da elite brasileira de Gonçalves Dias acentua o valor de tristeza do Império de sua experiência, e suas cisões subjetivas, melancólicas, com a própria realidade nacional, uma presença que é também, desde sempre, uma ausência. Tudo isto configurado, na poesia da menina, com elegância e precisão minimalista e concreta, digna de um poeta modernista futuro, talvez mais bandeiriana do que oswaldiana, e contado pelo escritor alemão em uma situação humana análoga àquela dos artistas e intelectuais plenamente modernos que, 150 anos depois, puderam anotar sobre um fenômeno semelhante da vida erótica nacional, olha que coisa mais linda, mais cheia de graça, é ela menina, que vem e que passa, num doce balanço, a caminho do mar. Algo deste mundo brasileiro, estético, conceitual e ético ao seu modo, já estava lá, no canto da menina que dança dentro da menina, do Rio de Schlichsthorst.

E também, pelo lado implícito da violência, na passagem estão cifrados os jogos sexuais culturais, o sexismo e o machismo tradicionais, próprios à cultura popular e ao modernismo populista brasileiro. Um mundo que tem origem nesta ampla negociação prática, que faz cruzar a visão do paraíso do corpo erótico da mulher, da negra ou da mulata brasileira, com o elogio erotizante do seu senhor, em busca de vantagens humanas possíveis frente à existência-limite do desamparo social e da ordem autoritária ao redor, que enquadra tudo. Que nega é essa? É o espaço erótico fundamental, sexualizado e negociado, que criou a cultura brasileira exatamente aí, entre o olhar desejante do senhor e o corpo funcionando como arma estética e erótica da escrava, para um virtual, e socialmente impossível, mútuo encontro, ou gozo. É a origem sexual real, fonte de cultura desde os corpos e também de violências sublimadas sem fim na expansão do espaço moderno brasileiro. 
Desta mútua, mas desequilibrada no poder, sedução e relação sexual na linguagem, e na vida, nasceria a máquina mulata brasileira, o complexo cultural imaginário, apoiado no corpo, da figura feminina popular de origem negra, figura aberta à miscigenação desde a origem nacional, que seria emblema e objeto da busca de mediação com o popular de nosso modernismo, e também do próprio sexismo e machismo populares brasileiros, com suas formas de longa duração que vão de Schlichsthorst a Di Cavalcanti e a Jorge Ben. Era o mundo concreto que daria origem à figura social da superexcitação sexual da mulata, e da mulher, brasileira, cantada em prosa e verso como civilização erótica baseada no balanço sensual do que era um corpo real - um duplo popular, feminino, do homem cordial, masculino, e dependente -, mulata ainda mais exposta ao erotismo pela indeterminação de seu lugar de classe e pela indeterminação do seu lugar de raça, como anotou Gilberto Freyre, produto mestiço desta relação social sexual, origem de povo e de cultura no Brasil. Porque a ação sexual de senhores e escravas diminuía a dor violenta do cativeiro, como gesto político utópico... ou a aumentava, como produção de cultura somente desde aí?

E o fato escandaloso de que um aventureiro alemão, de passagem pelo país, negociando a sua própria identidade e sonho com o daquela nova terra, pudesse enunciá-la com tanta precisão e graça, mas que, efetivamente, só no século xx brasileiro discursos modernistas pudessem chegar a se aproximar do país naqueles termos, revela, pela própria ausência histórica da nossa escritura nacional sobre a coisa ao seu tempo, uma outra dimensão, vetusta e casmurra, de nossa formação simbólica nacional na escravidão. Para não dizermos, como efeitos duradouros de cultura, plenamente burra, de valorização da vida não intelectual ou consequente. A única inteligência produzida ao longo do tempo da elite brasileira para a condição social que de fato produzia era a inteligência da sofismática volúvel, infernal, expressa como objeto crítico radical por Machado de Assis. É também uma tristeza do Império, a impossibilidade radical de poder simplesmente contar a sua própria realidade.

Porque jamais um novo brasileiro daqueles tempos da origem, com seus códigos portugueses e católicos de conduta, com seu entulho simbólico clássico dissociado do senso da história, poderia expor a verdade erótica ambígua daquele seu próprio mundo, todavia um mundo de grandes, imensos, privilégios, desde o poder do dinheiro global até o acesso direto aos corpos, para o trabalho e para o gozo, produzidos pela presença da vida escrava. Jamais ele poderia se ver como o novo nababo tropical, fazendeiro do ar das Índias Ocidentais, que de fato era, cultivando uma cultura erótica de acesso ao corpo feminino negro, de preguiça, de prazeres e de estética tropical, ou tropicalista, que se 
duplicava na vida ambígua, também convite interessado ao erotismo e à oscilação entre trabalho e preguiça, da própria casta trabalhadora, a grande escravaria urbana brasileira. Assim nenhum brasileiro do tempo poderia definir bem o que era o fado por exemplo - palavra que ecoa o sentido do trabalho estafante, e o destino -, a dança popular que deu origem ao samba moderno, nos termos entre reais e conceituais com que Schlichthorst realizou - por ter mobilidade geográfica, mobilidade de classes, mobilidade de corpo e de desejo e mobilidade de pensamento -, livre o suficiente para de fato ser simbolicamente livre no país tropical dos senhores e dos escravos - um país hiperdeterminado na mentalidade, mas quase experimental no mundo da vida: "o fado consiste num movimento trêmulo do corpo que, suavemente embalado, exprime os sentimentos mais sensuais de um modo tão natural como indecente".

Definição elegante, que deixa entrever os dois polos do encontro sexual e cultural das raças e dos poderes no Império tropical: algo do corpo natural, talvez da dança original africana que certamente devia ter outro caráter, e algo do corpo indecente, desta dança já referida às tramas sociais, de sedução, enfrentamento e desacato controlado da ordem de poder colonial/nacional brasileira, em que as escravas jogavam abertamente com o poder de acesso dos senhores ao seu corpo, e de simultânea negação pela cultura oficial deste próprio corpo. Um corpo simultaneamente natural e indecente, assim africano e brasileiro.

Nenhum brasileiro pode nomear ao seu tempo este mesmo mundo brasileiro, que também, em meio ao próprio terror, era composto de joias humanas, princesas à venda, como aquela menina descrita por Schlichthorst, um homem que, ao atravessar oceanos, continentes e sonhos para vir trabalhar no Brasil de 1820, meio como servo, meio como senhor, atravessou todas as estruturas simbólicas nacionais congeladas da época, e tocou pela primeira vez a cultura brasileira moderna, já formada nesta visão, dando-nos notícia fresca de uma de nossas primeiras artistas.

Tales Ab'Sáber é professor de Filosofia da Psicanálise da Unifesp e autor de, entre outros, $O$ sonhar restaurado (Editora 34, 2005), A música do tempo infinito (Cosac Naify, 2012) e Michel Temer e o fascismo comum (Hedra, 2018). 